\title{
Literature Review of Usage of Database Management Systems helps in Agriculture fields
}

\author{
D. S. R. Costa, G.W.S.S. Wickramarathne, D.M.J. Wickramasinghe \\ Department of Information Systems, Faculty of Management Studies, Rajarata University of Sri Lanka
}

\begin{abstract}
This includes a review of the uses and applications of Database Management Systems in the Agriculture field. Agriculture produces more products by cultivating certain plants and raising domestic animals. Furthermore, this includes the Design of the Agricultural Database, Functions of Farm Level DBMS to Farmers. The middle part discusses the information of Database in Livestock, Uses of Livestock database management systems, Database in Cropping, Crop - Soil Database Management, Uses of Crop - Soil Database, Objectives of Crop Soil Database, Uses of databases for remote detection of crops, DBMS for Watering Function in Agriculture, and finally Overall Usage and importance of Databases Management Systems.
\end{abstract}

\section{INTRODUCTION}

$\mathrm{T}$ his literature review describes the use and applications of Database Management Systems (DBMS) in the Agriculture field. Agriculture is one of the oldest industries in the world. All of the countries in the world have many kinds of agriculture sectors. With development of technology, every industry in the world adapts to use technological support to develop their industries. The agriculture field was also developed with Information Technology.

Agriculture can describe in many ways, such as plants and animals sustain humans worldwide by providing food and other agricultural products. Different properties are also used to define specific agricultural forms, such as soil type, frequency of cultivation, and major crops or animals.

Agriculture is limited to crop cultivation, and except for domestication, it generally implies both activities. The word "agriculture" derives from the Latin ager (field) and colo (cultivate), signifying, when combined, the Latin agriculture: field or land tillage (Harris \& Fuller, 2014). Agricultural Sector can be divided into four sub-sectors, namely: Crops, Livestock (both production and animal health), Fisheries and Aquaculture (including capture fisheries), and Forestry(World Bank, 2007).

Agriculture is the main point of the economy of lots of countries and contributes to the development of the economy. In addition, it guides the process of economic prosperity in developed countries (Hindawi, 2018). Several research studies have concluded that about $70 \%$ of the world's agriculture receives freshwater, and the total irrigated land area is declining due to the rapid increase in food demand and global warming (Hindawi, 2018).
An evolutionary model for agriculture that separates transitions between cultivation, domestication, and agriculture and suggests potential archaeological indicators. Soil type, frequency of cultivation, and primary crops or animals are used to define specific types of agriculture.

\section{DATABASE MANAGEMENT SYSTEM}

Databases play an essential role in making accurate and healthy decisions (Celikyurek, Karakus, Aygun, \& Tas, 2019).A database is usually a collection of related, structural information or data stored electronically in a computer system. A DBMS usually controls a database. Database systems are the collection of Data and their associated applications. Every database, whether on paper or a handheld electronic organizer or a computer - contains tables of records. A database contains information collected on an individual or an organization(Derclaye \&Husovec, 2005).

DBMS is a collection of interconnected data and programs to access that data. The main purpose of DBMS is to store and retrieve information quickly and efficiently from a database (Sharma, Karamchandani, Dave, Patel, \& Doshi, 2022) and DBMS is to allow the users to define, store, retrieve and update the information in the database on demand withcan refer to a person or a company(Chatterjee, 2017).

\section{Database Management System for Agriculture Sector}

Many agricultural producers keep and analyze their records using computerized DBMS. Very powerful DBMS now available for desktop computers are used in various agricultural applications. Machinery, crop, livestock, and payroll records are all commonly maintained with DBMS(Saiz-Rubio, \& Rovira_Mas, 2020).When designing a database for the agricultural field, the main entities, attributes, relationships, and constraints must be identified. Primarily use Crops specialization, Product specialization, Production, Export, Product usage, company description, institute description, weeds, intercropping, intercrop disease, soil, fertilizers, and land description (Punchihewa, \&Wimalaratne, 2010)

\section{Functions of Farm Level DBMS to Farmers}

Allows on-farm mapping using differential global positioning system (DGPS) data or accepting DGPS signals are used for modifying or creating georectified data. Then these data can be converted into map layers. These georectified maps include 
yield maps, soil sampling maps, field boundary maps, and weed-pest infestation maps, and they are accepted by outside sources.These maps allows for the store farm records related to spatial data and farm operations in a spatial database. Furthermore, these agricultural DBMS helps to store long term information such as: soil maps, farm maps, landscape maps, etc. and same as short term information such as: annual field maps, crop records, animal records, environmental conditions, weather conditions, pest records, etc. Moreover, they can keep records of fertilizer, chemical records, flood maps (Sarmah, Deka, Sharma, \& Sarma, 2018).

\section{Database in Livestock}

Databases are widely used today for livestock. It benefits in many areas such as herd management, regional and national breeding projects, milking, meat quality, milk structure composition, animal trade, counting, weighing, diagnosis, low yield detection, animal selection - a collection of information on breeders and enterprises used as animals and history of meat in the market. (Celikyurek, Karakus, Aygun, \& Tas, 2019)

Furthermore,Voulodimos (2010) says that keeping such information about animals in a database will enable farmers to collect information about their animals quickly. The Farmer menu allows you to view the complete animal list and includes functional categories. Animal's born with tagging process, weaning, observations of milk production, wool production, animal weighing, animal nutrition, leave from the farm such as sales, loss, and theft. Farmers can generate this kind of charts by using databases information more beneficial.

Long data stored in livestock businesses for a long time to determine the productivity of animal products, reveal animal breeding values, meet suitable breeding needs, establish effective, productive breeding organizations, generate high income and keep and keep animals. Data will play a crucial role. For these purposes, it is essential to keep animal husbandry data in the database for an extended period (Celikyurek, Karakus, Aygun, \& Tas, 2019).

\section{Database in Cropping}

A database for crops is created to analyze which crop is suitable, the temperature conditions suitable for the desired crop, and much more. (Ramya, 2019). An in-depth understanding of plant metabolism helps to enhance their growth and yield. (Grafahrend-Belau, 2007). The database is helping in crop as Crop records with basic information about the crop's scientific name and family name. (Nizar, 2010), the agro-ecology table is used to store the requirements of agroecological of the crop, such as temperature, rainfall, soil depth, $\mathrm{pH}$ value, and soil texture. Furthermore, details about climate crop classification are also included (Nizar, 2010).

\section{Database in Soil}

This can be very useful when designing a GUI application to access crop selection by feeding the soil parameters of the application. This way, it will be much easier for farmers to predict the crop with the help of software. Other crop soil mapping methods can be used in conjunction with the proposed method to test the practical implementation. Using the required database will increase crop diversity. In addition, the interactions of different variables in the soil corresponding to the crop can be analyzed.It is essential to assess crop production for various policy decisions related to storage, delivery, pricing, marketing, import, and export (Singh, 2019).

\section{Uses of Crop - Soil Database}

Crop diversification is a time-consuming process, and if farmers go for a particular crop, it will affect crop production and soil fertility.The crop-soil database is straightforward for the local farmer to predict the crop for their soil. This way, they can grow different crops and save water and soil fertility(Singh, 2019).

\section{Uses of databases for remote detection of crops}

Database systems, which allow the compilation of aggregated datasets for a wide range of agricultural-related measurements under a variety of conditions, can, if established, become a tool as a data source for hypothetical testing and validation. Such systems will further open up machine learning methods for prediction using large, quality-controlled datasets.

Such systems should be based on data collection protocols and metadata descriptions that increase the ability to transfer data between functional groups. (Hueni et al., 2018).

\section{DBMS for Watering Function in Agriculture}

Water it plays an essential role in agricultural production. It is in charge of crop growth and production and the effectiveness of other inputs such as seeds, fertilizers, and pesticides. Water availability must be adequate, timely, and reliable for agricultural yields to be assured.

Pressurized Irrigation Systems (PIS) is one of the developed Database Management Systems introduced to enhance water use efficiency. PIS in the form of drip sprinklers helps save water, energy, fertilizer, and labor, reduce disease and increase crop production with quality. Therefore, this tool will be helpful for farmers. (Manibhushan, Upadhyaya, \&Singh, 2014)

\section{USAGE AND IMPORTANCE OF THE DBMS}

From the past to the present, both methods of keeping records, keeping them for a long time, reusing them when needed, accessing the desired information quickly, and filtering records according to specific features have been extensively explored in animal husbandry and other fields (Celikyurek, Karakus, Aygun, \&Tas, 2019). In DBMS, information can be shared among users quickly and efficiently, and data independence is also an essential factor of DBMS. 


\section{CONCLUSION}

In the past, there was no database management for agriculture. However, nowadays, the agriculture sector has many benefits from the database management system. In addition to that, the specialty of each of the fields in agriculture was that even a database had been created by now. One of the significant advantages of this database is that it stores all the data related to each field to be viewed anytime, anywhere, when needed. This DBMS can be identified as one of the reasons for the gradual growth of agriculture today than in the past.

This review describes how database usage has affected livestock, watering systems, forestry management, and poultry management. Also, when looking at the database comparison, you can get a rough idea of how they differ from the features of these databases, and this literary review will give you an overview of how this database is included in agriculture development.

\section{REFERENCES}

[1]. Sarmah, K., Deka, C. R., Sharma, U., \&Sarma, R. (2018). Role of GIS-based technologies in sustainable agriculture resource planning \& management using spatial decision support approach. Int J Innov Res EngManag, 5(1), 30-34.

[2]. Celikyurek, H., Karakus, K., Aygun, T., \& Tas, A. (2019). Database Usage and Its Importance in Livestock. Manas Journal of Agriculture Veterinary and Life Sciences, 9, 117-121.

[3]. Chatterjee, A. (2017). (R15A0509) DATABASE MANAGEMENT SYSTEMS. Kompally: Malla Reddy College of Engineering \& Technology.

[4]. Derclaye, E., \&Husovec, M. (2021). Sui Generis Database Protection 2.0: Judicial and Legislative Reforms. Available at SSRN 3964943.
[5]. Eva Grafahrend-Belau, S. W. (2007, October 11). MetaCrop: a detailed database of crops. Nucleic Acids ResearchMetaCrop, 36. DOI:doi:10.1093/nar/gkm835

[6]. Harris, D., \& Fuller, D. (2014, January). Agriculture: Definition and Overview. Encyclopedia of Global Archaeology, 104-113. doi:10.1007/978-1-4419-0465-2_64

[7]. Hindawi. (2018). Monitoring and Control Systems in Agriculture. Journal of Sensors, 18. Retrieved from https://www.hindawi.com/journals/js/2018/8672769/

[8]. Hueni, A., Suárez, L., Chisholm, L., Held, \& Alex. (2018, December). The Use of Spectral Databases for Remote Sensing of Agricultural Crops. In book.

[9]. Punchihewa, D. J., \&Wimalaratne, P. (2010). Towards an ICTenabled farming Community. E-Governance in Practice, India, 201-207.

[10]. Sharma, A., Karamchandani, A., Dave, D., Patel, A., \&Doshi, N. (2022). Database Management Systems-An Efficient, Effective, and Augmented Approach for Organizations. In ICT with Intelligent Applications (pp. 465-478). Springer, Singapore.

[11]. Manibhushan, Upadhyaya, A., \& Kumar Singh, A. (2014). Database Management System for Design and Layout. Journal of AgriSearch, 112-116.

[12]. Nur Marahaini Mohd Nizar, E. J. (2010, October). Open Data to Support Agricultural Diversification. Data in Brief. Retrieved from https://www.journals.elsevier.com/data-in-brief

[13]. Ramya, R. P. (2019). Design and Development of Crop Database Website to help Farmers. TARGET, 7.

[14]. Saiz-Rubio, V., \&Rovira-Más, F. (2020). From smart farming towards agriculture 5.0: A review on crop data management. Agronomy, 10(2), 207.

[15]. Singh, D. A. (2019, DECEMBER 12). Crop- Soil Data Management System Of Cropping. INTERNATIONAL JOURNAL OF SCIENTIFIC \& TECHNOLOGY RESEARCH, 8.

[16]. Voulodimos, A. a. (2010, 03). A complete farm management system based on animal identification. Computers and Electronics in Agriculture, 70, 380-388.

[17]. World Bank. (2007). World development report 2008: Agriculture for development. The World Bank. 